\section{Malnutrition, Mortality and Breastfeeding Practices in the Eastern Mediterranean Region: A Review of the Current Status}

\section{Abstract}

Background: Countries in the Eastern Mediterranean region (EMR) are facing many challenges that hinder progress in reduction of mortality rates (MRs) and nutritional status of children under-five years of age (CU5). Hence there is a need to identify breastfeeding practices that can influence malnutrition and MRs in the region.

Aim: To analyze regional data of malnutrition, mortality and breastfeeding practices in mothers and CU5 in the EMR countries.

Methods: Data from regional surveys of WHO and UNICEF for nutritional status and MRs in the EMR countries were analyzed in total and by income group and correlated to breastfeeding practices including timely first suckle (TFS), exclusive breastfeeding (EBF), breastfeeding rates at 12 (BR12) and 24 months (BR24) and percent designated Baby-friendly hospitals (DBFH). MRs included neonatal mortality rates (NMR), infant mortality rates (IMR), under-five mortality rates (U5MR), maternal mortality ratio (MMR). Selected indicators for development included illiteracy rates and total fertility rates (TFR).

Results: Practices of early initiation (TFS), EBF, and continuity of breastfeeding are low in the region. MRs correlated with percent DBFH, TFS, EBF. Also BF12 and BF24 months correlated with stunting, wasting in the CU5, U5MR and overweight and obesity in adults. MRs correlated highly with stunting and wasting and poorly with overweight or obesity in CU5. Other variables as illiteracy, TFR, obesity and overweight in adults correlated significantly with MRs and with breastfeeding duration. At country level the low trends of shortened breastfeeding duration were associated with the high MRs and malnutrition rates.

Conclusion: Suboptimal early feeding practices, low EBF and declines in breastfeeding duration impact child growth and survival and are associated with high stunting, wasting, overweight and mortality in CU5. Indices of development as improving literacy, birth spacing and can also help improve survival of children and mothers in the region.

Keywords: Breastfeeding duration; Childhood mortality rates; Nutritional status; Stunting; Wasting; Overweight; Baby-friendly hospitals; Development indices
Ayoub Al-Jawaldeh ${ }^{1}$ and AzzaAbul-Fadl ${ }^{2}$

1 Vienna University, Austria

2 Benha Faculty of Medicine, Benha University, Egypt

\section{*Corresponding author: AzzaAbul-Fadl \\ झ azza_abulfadl@yahoo.com}

Benha University, Cairo, Egypt.

Tel: +20223494183

Citation: Al-Jawaldeh A, AzzaAbul-Fadl (2018) Malnutrition, Mortality and Breastfeeding Practices in the Eastern Mediterranean Region: A Review of the Current Status. J Ped Care. VOL.4 No.1:2

\section{Introduction}

It is estimated that around 5.6 million children under-five years of age died in 2016. The number of under-five deaths worldwide has declined by half since 1990, from 12.7 million to 5.6 million in 2016. Malnutrition, which is a consequence of poor nutrition and repeated infections, is the underlying cause of death in around one third of all deaths among these children of which one half can be averted by optimal breastfeeding practices [1]. These include exclusive breastfeeding for six months and continued breastfeeding for two years. They are especially critical to prevent diarrhoea and pneumonia, which are the 
two major causes of death in infants and young children [1,2]. Promoting, protecting and supporting breastfeeding through the Baby-friendly Hospital Initiative (BFHI) is a global initiative lead by UNICEF and WHO in 1991 [3] and updated in 2009 [4] and again in 2017 [5] and aims at improving exclusive breastfeeding rates by implementing the Ten steps to successful initiation and continuation of breastfeeding. The updates in the BFHI targeted strengthening of the implementation of the WHO Code of Marketing of Breast-milk Substitutes and its subsequent relevant World Health Assembly (WHA) resolutions (The Code) in maternity health care facilities [6]. Hence the support of early, exclusive and continued breastfeeding into the first and second years of life have short and long-term outcomes on child health, growth and development over their life span and influence their survival [7-9].

Several studies have discussed the mechanism by which breastfeeding can reduce mortality and improve the growth and development of children. Of these the NEOVITA study group showed that initiation of breastfeeding as early as possible immediately after birth or as soon as mother and baby can respond, is a means for saving lives and ensuring successful breastfeeding. Although this practice is already part of WHO recommendations for newborn care, it is not a universally applied, as only one half of the newborn babies are being breastfed in the first hour of life which is a core practice of step 4 of the Ten steps of BFHI $[8,10]$. Studies have shown that initiating breastfeeding in the first hour skin-to-skin contact between mother and baby up to the first suckle (TFS) can reduce neonatal mortality by $22 \%$ and have later effects on reducing mortality in infancy too [11]. This is particularly important for low income and countries and communities in the Eastern Mediterranean Region (EMR) which are facing chronic emergencies, where malnutrition, neonatal and infant mortalities are high.

Promoting optimal breastfeeding practices can improve survival indirectly by influencing Sustainable Development Goals (SDGs). New analysis shows an investment of US\$4.70 per newborn could generate US\$300 billion in economic gains by 2025 . The Global Breastfeeding Scorecard, which evaluated 194 nations, found that only 40 per cent of children younger than six months are breastfed exclusively (given nothing but breastmilk) and only 23 countries have exclusive breastfeeding rates above 60 per cent [10]. Breastfeeding promotion can improve survival indirectly by promoting cognitive development [12-14] and mother health by reducing risk of breast and probably ovarian cancer, which are two leading causes of death among women in both developed and developing countries $[7,13]$. Investment in breastfeeding promotion can save the lives of 520,000 children under the age of five and produce economic gains of US\$300 billion over a decade of time by reducing expenditure and lives years lost due to illness and disability [ 9,12-14].

Although breastfeeding has been shown to be the most effective intervention for reducing mortality rates in children and mothers $[10,11]$, there are still the challenge on how to increase exclusive breastfeeding rates and breastfeeding continuity for reducing morbidity and mortality in the region. Also, there are still gaps in understanding the relation between mortality, malnutrition, breastfeeding and development in the EMR [10]. Drawing on such issues may assist countries in the EMR to improve, monitor and predict health outcomes and survival of children and mothers, and prevent adverse outcomes of early infant feeding practices in the EMR.

\section{Methodology}

\section{Study design and data sources}

Data from the World Health Organization (WHO)-EMRO Framework for Health Information Systems in 2017 [15] and core indicators for monitoring health situation and health system performance for 2015 and 2017 for the 22 countries of the EMR region $[16,17]$. Missing data was completed from the UNICEF Multicenter Indicator Cluster Surveys (MICS) of UNICEF accessed on mics.unicef.org [18]. The results from the most recent MICS surveys which were carried out from 1995 are becoming progressively available online and are updated for countries every 3 to 5 years. The data for life expectancy were retrieved from the WHO World Health Statistics 2016 Monitoring Health for SDGs (Sustainable Development Goals) [15]. Breastfeeding rates at 12 months and 24 months were retrieved from UNICEF MICS surveys [18], demographic health surveys or national surveys conducted by the countries. All data reflected the period between 2010 to 2016.

\section{Data selected and data analysis}

Data were compiled in excel sheets and statistically analyzed manually. The nutritional status for the 22 countries of the EMR were analyzed and correlated to breastfeeding rates for timely first suckle (TFS), exclusive breastfeeding (EBF), breastfeeding at 12 (BF12) and 24 months (BF24) in children under five years of age (CU5), overweight and obesity in adults. The breastfeeding rates were defined as follows: TFS is defined as early initiation of breastfeeding within the first hour immediately after birth. EBF was measured from data bases and represents babies fed only on mother's milk from birth up to 5 months of age (0-5 months) with no introduction of bottles, pacifiers, drinks or other milks or even water (except for medicine or vitamin drops). Breastfeeding at 12 and 24 months is defined as mothers who were still breastfeeding prior to this age whether or not child was receiving other adequate foods or bottles or pacifiers and irrespective of frequency or duration of breastfeeding.

The data for the Baby-Friendly Hospital Initiative (BFHI) was obtained from the WHO report on national implementation [17] conducted for 120 countries in the world. Data extracted for the EMRO countries included percent designated Baby-friendly hospitals (DBFHs). Missing and updated data was obtained by direct contact with the WHO offices in the countries of the region.

Mortality rates included the neonatal mortality rate (NMR) per 1000 live births, infant mortality rate (IMR) per 1000 live births, under-five mortality rate (U5MR) per 1000 live births and maternal mortality ratio (MMR) per 100,000. Also, some selected indicators for development including literacy rates, 
total fertility (TFR) and population growth rates, overweight and obesity in adults, were studied as contributory factors to MRs and malnutrition in children and maternal survival.

Countries of the EMR were further classified by income groups as follows: High income countries (HIC) including Bahrain, Kuwait, Oman, Qatar, Saudi Arabia and United Arab Emirates (UAE); Middle income countries (MIC) including Egypt, Jordan, Iran, Iraq, Lebanon, Libya, Morocco, Palestine and Syria, Tunisia; and Lowincome countries (LIC) including Afghanistan, Djibouti, Pakistan, Sudan, Somalia and Yemen.

\section{Statistical analysis}

The collected data were organized, tabulated and statistically analyzed using SPSS version 20 (SPSS Inc; Chicago, Illinois), running on IBM compatible computer with Microsoft Windows 7 Operating System. The qualitative data for the rates of breastfeeding, literacy, mortality rates and nutritional indices were presented as discrete data per country and also presented in mean and standard deviation for the region. Spearman rank correlation coefficient was used to measure the strength and direction of the linear relationship between two variables. The level of significance cut off used was $\mathrm{P}<0.05$.

\section{Ethical considerations}

The work of the paper was in compliance with the ethical principles of Helsinki Declaration in 1964.

\section{Results}

Correlation studies between breastfeeding practices with malnutrition rates and mortality rates for children and mother and other factors that can influence mortality in EMR countries (Table 1). Correlations between mortality with nutritional status in children and adults and selected indicators of development in the EMR countries (Table 2). Correlation of breastfeeding practices with maternal and early childhood mortality rates by the level of income in the EMR (Table 3).

Table 1 Correlation studies between breastfeeding practices with malnutrition rates and mortality rates for-children and mother-and other-factors that can influence mortality in EMR-countries.

\begin{tabular}{|c|c|c|c|c|c|}
\hline $\begin{array}{l}\text { Breastfeeding practices } \\
\text { (number-of countries) }\end{array}$ & $\begin{array}{l}\text { Timely First } \\
\text { Suckle (18) }\end{array}$ & $\begin{array}{l}\text { Exclusive breastfeeding } \\
(0-5 \mathrm{mo})(22)\end{array}$ & $\begin{array}{l}\text { Breastfeeding at } 12 \\
\text { months (22) }\end{array}$ & $\begin{array}{l}\text { Breastfeeding at } 24 \\
\text { months (22) }\end{array}$ & $\begin{array}{l}\text { p-Value (level of } \\
\text { significance) }\end{array}$ \\
\hline \multicolumn{6}{|c|}{ Nutritional status in under-fives } \\
\hline Stunting (22) & $r-0.09$ & $r-0.05$ & $r-0.38$ & r0.48* & $* P<0.05$ \\
\hline Wasting (22) & $r-0.22$ & $r-0.13$ & $r-0.36$ & r0.49* & $* P<0.05$ \\
\hline Overweight (20) & $\mathrm{r}-0.51$ & $r-0.11$ & $r-0.05$ & $\mathrm{r}-0.36$ & \\
\hline Obesity (15) & $r-0.51^{*}$ & $r-0.22$ & $r-0.475^{*}$ & $r-0.33$ & $* P<0.01$ \\
\hline \multicolumn{6}{|c|}{ Mortality rates of children and mothers (22) } \\
\hline NMR-per-1000 & $r-0.06$ & $\mathrm{r}-0.02$ & $r-0.35$ & $\mathrm{r}-0.39$ & $P>0.05$ \\
\hline IMR-per-1000 & $r-0.13$ & r-0.07 & $r-0.39$ & $\mathrm{r}-0.39$ & $P>0.05$ \\
\hline U5MR-per-1000 & $\mathrm{r}-0.13$ & $\mathrm{r}-0.11$ & $r-0.44$ & $r-0.46^{*}$ & $P<0.05$ \\
\hline MMR-per-100,000 & $r-0.125$ & $\mathrm{r}-0.15$ & $r-0.27$ & $r-0.27$ & $P>0.05$ \\
\hline \multicolumn{6}{|c|}{ Selected developmental indices } \\
\hline Literacy (Total) (22) & $r-0.13$ & $r-0.09$ & $r-0.37$ & $r-0.43$ & $P>0.05$ \\
\hline Literacy (Female) (22) & $r-0.08$ & $r-0.12$ & $r-0.26$ & $\mathrm{r}-0.21$ & $P>0.05$ \\
\hline Total fertility rate (22) & $r-0.29$ & $r-0.03$ & $r-0.27$ & $r-0.36$ & $P>0.05$ \\
\hline
\end{tabular}

Table 2 Correlations between mortality with nutritional status in children and adults and selected indicators of development in the EMR-countries.

\begin{tabular}{|c|c|c|c|c|c|c|}
\hline $\begin{array}{c}\text { Mortality rates } \\
\text { UN-IGME } 2015 \text { estimates }\end{array}$ & Mean \pm SD & $\begin{array}{l}\text { MMR-per-100,000 } \\
\text { live births }\end{array}$ & $\begin{array}{c}\text { Neonatal MR- } \\
\text { per-1000 live births }\end{array}$ & $\begin{array}{c}\text { Infant MR- } \\
\text { per-1000 live births }\end{array}$ & $\begin{array}{l}\text { U5MR-per-1000 } \\
\text { live births }\end{array}$ & $\begin{array}{l}\text { (P-value) Level of } \\
\text { significance }\end{array}$ \\
\hline \multicolumn{7}{|c|}{ The Baby Friendly Hospital Initiative (BFHI) } \\
\hline Percent designated BFH (19) & $37.7 \pm 88.9$ & $r-0.44$ & $r-0.51^{*}$ & $r-0.51^{*}$ & $r-0.47^{*}$ & $P<0.05$ \\
\hline \multicolumn{7}{|c|}{ Under-nutrition in children under-five years of age } \\
\hline LBW & $14.1 \pm 10.3$ & $r-0.51^{*}$ & $r-0.68^{*}$ & $r-0.57^{*}$ & $\mathrm{r}-0.51^{*}$ & $\begin{array}{l}\mathrm{P}<0.001^{* *} \\
\mathrm{P}<0.01^{*}\end{array}$ \\
\hline Stunting (22) & $19.2 \pm 14.9$ & $\mathrm{r}-0.79 * *$ & $\mathrm{r}-0.87^{* *}$ & $r-0.85 * *$ & $r-0.82 * *$ & $P<0.001^{* *}$ \\
\hline Wasting (22) & $8.8 \pm 7.26$ & $r-0.52 *$ & $\mathrm{r}-0.55^{*}$ & $\mathrm{r}-0.55^{*}$ & $\mathrm{r}-0.53^{*}$ & $\mathrm{P}<0.01^{*}$ \\
\hline \multicolumn{7}{|c|}{ Over-nutrition in children under-five years of age (CU5) } \\
\hline Overweight (21) & $9.11 \pm 6.03$ & $r-0.41$ & $r-0.28$ & $r-0.32$ & $r-0.34$ & $P>0.05$ \\
\hline Obesity (15) & $4.5 \pm 4.1$ & $r-0.39$ & $r-0.26$ & -0.28 & $r-0.28$ & $P>0.05$ \\
\hline \multicolumn{7}{|c|}{ Nutritional status in adults } \\
\hline Overweight (22) & $54.7 \pm 19.5$ & $\mathrm{r}-0.80 * *$ & $\mathrm{r}-0.94 * *$ & $r-0.93 * *$ & $\mathrm{r}-0.89 * *$ & $\mathrm{P}<0.001 * *$ \\
\hline
\end{tabular}




\begin{tabular}{|c|c|c|c|c|c|c|}
\hline $\begin{array}{l}\text { Mortality rates } \\
\text { UN-IGME } 2015 \text { estimates }\end{array}$ & Mean \pm SD & $\begin{array}{l}\text { MMR-per-100,000 } \\
\text { live births }\end{array}$ & $\begin{array}{c}\text { Neonatal MR- } \\
\text { per-1000 live births }\end{array}$ & $\begin{array}{c}\text { Infant MR- } \\
\text { per-1000 live births }\end{array}$ & $\begin{array}{l}\text { U5MR-per-1000 } \\
\text { live births }\end{array}$ & $\begin{array}{l}\text { (P-value) Level of } \\
\text { significance }\end{array}$ \\
\hline Obesity (22) & $\begin{array}{c}24.49 \pm \\
11.87\end{array}$ & $\mathrm{r}-0.79 * *$ & $\mathrm{r}-0.93^{* *}$ & $\mathrm{r}-0.93 * *$ & $\mathrm{r}-0.90^{* *}$ & $\mathrm{P}<0.001 * *$ \\
\hline \multicolumn{7}{|c|}{ Selected development indicators that can influence mortality in children and mothers } \\
\hline Literacy (Total) (22) & $81.9 \pm 22.7$ & $r-0.87^{*}$ & $\mathrm{r}-0.87^{*}$ & $r-0.95^{*}$ & $r-0.96 * *$ & $\mathrm{P}<0.001 * *$ \\
\hline Literacy (Female) (22) & $75 \pm 29.87$ & $\mathrm{r}-0.59$ & $\mathrm{r}-0.70^{*}$ & $\mathrm{r}-0.74 * *$ & $\mathrm{r}-0.72 * *$ & $\begin{array}{l}\mathrm{P}<0.001^{* *} \\
\mathrm{P}<0.01^{*}\end{array}$ \\
\hline TFR-(22) & $3.3 \pm 1.3$ & $\mathrm{r}-0.79$ & $r-0.73 *$ & $\mathrm{r}-0.81 *$ & $\mathrm{r}-0.81 *$ & $\mathrm{P}<0.001 * *$ \\
\hline Population growth (22) & $3.1 \pm 2.75$ & $r-0.15$ & $r-0.276$ & $\mathrm{r}-0.22$ & $\mathrm{r}-0.19$ & $P>0.05$ \\
\hline
\end{tabular}

Table 3 Correlation of breastfeeding practices with maternal and early childhood mortality rates by the level of income in the EMR.

\begin{tabular}{|c|c|c|c|c|c|}
\hline Breastfeeding rates & Mean \pm SDs & NMR-per-1000 & IMR-per-1000 & U5MR-per-1000 & MMR-per-100,000 \\
\hline \multicolumn{6}{|c|}{ High Income Countries } \\
\hline Timely first suckle & $60.25 \pm 27.8$ & ISD & ISD & ISD & $r-0.23$ \\
\hline Exclusive breastfeeding & $32.02 \pm 20.37$ & $r-0.61 *$ & $r-0.53 *$ & $r-0.47^{*}$ & $r-0.36$ \\
\hline Breastfeeding at $12 \mathrm{mo}$ & $51.31 \pm 21.75$ & $r-0.37$ & $r-0.34$ & $\mathrm{r}-0.26$ & $r-0.82 * *$ \\
\hline Breastfeeding at 24 mo & $22.29 \pm 14.59$ & $r-0.08$ & $r-0.17$ & $\mathrm{r}-0.15$ & $\mathrm{r}-0.79 * *$ \\
\hline \multicolumn{6}{|c|}{ Middle Income Countries } \\
\hline Timely first suckle & $41.7 \pm 24.2$ & $\mathrm{r}-0.16$ & $r-0.17$ & $r-0.17$ & $r-0.16$ \\
\hline Exclusive breastfeeding & $35.6 \pm 16.63$ & $\mathrm{r}-0.01$ & $\mathrm{r}-0.05$ & $r-0.09$ & $r-0.38$ \\
\hline Breastfeeding at $12 \mathrm{mo}$ & $60.27 \pm 17.5$ & $r-0.53^{*}$ & $r-0.49 *$ & $r-0.51 *$ & $r-0.29$ \\
\hline Breastfeeding at $24 \mathrm{mo}$ & $24.03 \pm 15.38$ & $r-0.43$ & $r-0.02$ & $r-0.005$ & $r-0.074$ \\
\hline \multicolumn{6}{|c|}{ Low Income countries (LIC) } \\
\hline Timely first suckle & $57.7 \pm 12.08$ & $r-0.61^{*}$ & $r-0.27$ & $r-0.2$ & $r-0.09$ \\
\hline Exclusive breastfeeding & $25 \pm 23.79$ & $\mathrm{r}-0.24$ & $r-0.02$ & $r-0.13$ & $r-0.57^{*}$ \\
\hline Breastfeeding at $12 \mathrm{mo}$ & $70.34 \pm 20.45$ & $\mathrm{r}-0.12$ & $r-0.39$ & $r-0.37$ & $r-0.45^{*}$ \\
\hline Breastfeeding at $24 \mathrm{mo}$ & $35.96 \pm 21.11$ & $r-0.24$ & $r-0.15$ & $r-0.10$ & $r-0.43$ \\
\hline
\end{tabular}

ISD: insufficient data ( 3 countries reported data for-TFS which was not enough to estimate correlation). ${ }^{*} P<0.05,{ }^{*} * P<0.01$ and ${ }^{* * *} P<0.001$ (statistically significant), P>0.05 (not statistically significant). NMR: Neonatal Mortality Rate, IMR: Infant Mortality Rate, Under-Five Mortality Rate, MMR: Maternal Mortality Ratio Per-100,000 Live Births, UN-MMEIG (United Nation Maternal Mortality Estimation Interagency Group), 2015 Estimate (WHO-EMR, 2017).

\section{Findings}

\section{Breastfeeding practices and mortality rates}

There were no significant correlations between TFS and EBF with LBW, stunting, wasting or overweight, obesity in the under-fives. BF24 was significantly correlated with stunting $(r-0.5)$ at $\mathrm{P}<0.05$ and with wasting $(0.5)$ at $P<0.05$ and obesity with BF12 $(r-0.48)$ at $P<0.05$. TFS and EBF were not correlated with NMR, IMR, U5MR and $\mathrm{MMR}$ at $\mathrm{P}>0.05$ as shown in Table 1.

\section{Mortality rates and nutritional status}

Stunting correlated highly with NMR $(r-0.87)$, IMR $(r-0.85)$ and U5MR $(r-0.82)$ at $\mathrm{P}<0.001, \mathrm{P}<0.001$ and $\mathrm{P}<0.001$ respectively. Wasting correlated with NMR $(r-0.55)$, IMR $(r-0.55)$ and U5MR ( $r$ 0.53) at $P<0.01, P<0.01, P<0.05$ respectively. Low birth weight (LBW) correlated significantly with NMR ( $r-0.68)$, IMR ( $r-0.57)$ and U5MR ( $r 0.51$ ) with at $\mathrm{P}<0.01, \mathrm{P}<0.01$ and $\mathrm{P}<0.05$ respectively as shown in Table 1.

Overweight correlated poorly with NMR ( $r-0.29)$, IMR ( $r-0.32)$ and U5MR $(r-0.34)$ respectively at $P>0.05$. Similarly, obesity showed poor correlations with mortality rates for children at $\mathrm{P}>0.05$. However, in adults U5MR was significantly correlated with overweight $(r-0.89)$ at $\mathrm{P}<0.001$, and obesity $(r-0.9)$ at $\mathrm{P}<0.001$ as shown in Table 2.

Figure 1 demonstrates that there were positive trends in relationships between stunting, wasting and overweight with mortality rates for NMR and IMR in CU5 for the 22 countries of the EMR.

Figure 2 demonstrates the country trends of breastfeeding duration (at 12 months) with high nutritional indices for stunting, wasting and overweight in children under-five of age in the 15 countries of the EMR. Low BF12 is shown to be associated with increased rates of malnutrition by country.

Figure 3 demonstrates the country trends of breastfeeding duration (at 24 months) with mortality rates for NMR and IMR in CU5 of age in the 17 countries of the EMR. Low BF24 was shown to be associated with increased mortality rates by country (Figures 1-3).

Maternal mortality ratio (MMR) correlated with LBW ( $r-0.51)$, 


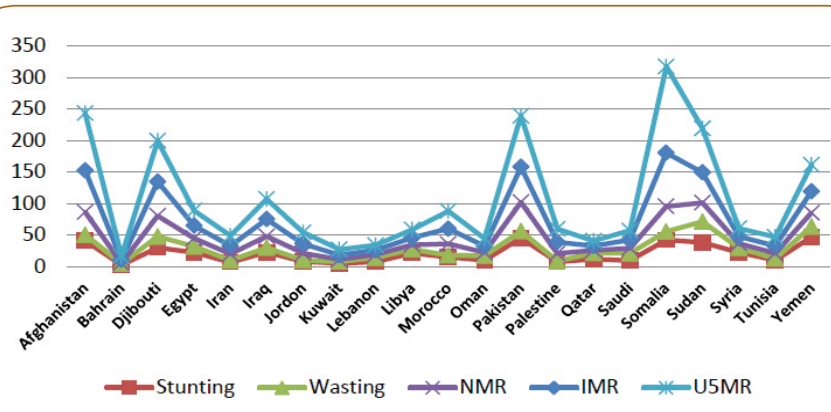

Figure 1 Relationship of stunting and wasting with mortality rates in children under-five of age in the 21 countries of the Eastern Mediterranean region.

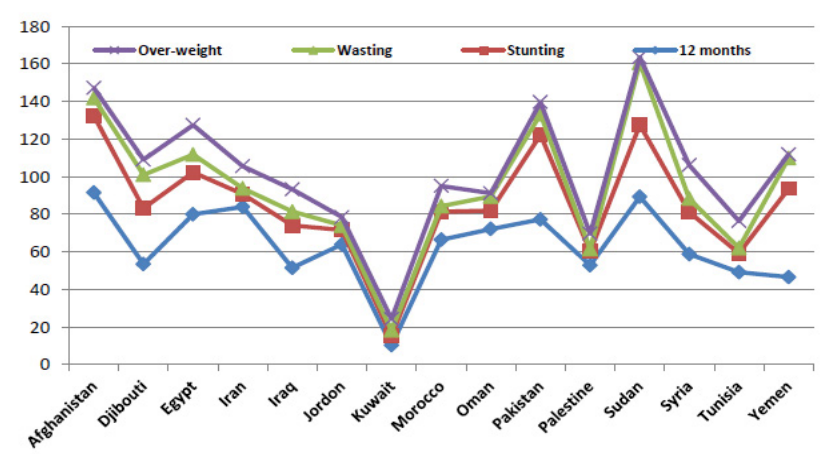

Figure 2 Relationship of breastfeeding to 12 months with stunting, wasting and overweight in children under-five of age in 15 countries of the Eastern Mediterranean region.

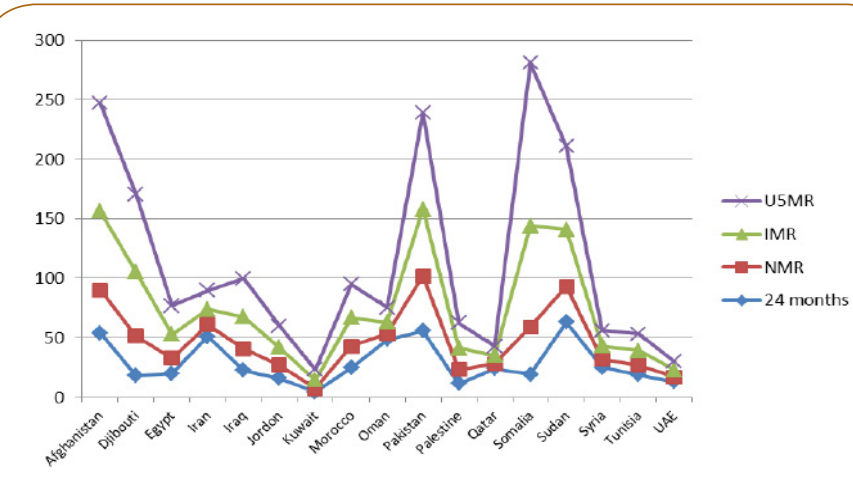

Figure 3 Relationship of breastfeeding to 24 months with neonatal mortality rate, infant mortality rate and under-five mortality rate in 17 countries of the Eastern Mediterranean region.

stunting $(r-0.79)$ in children under five of age at $P<0.05, P<0.001$ respectively, but poorly with overweight and obesity in children under five of age ( $r-0.39, r-0.39$ respectively) at $P>0.05$ as shown in Table 2.

\section{Mortality rates and developmental indices related to literacy and fertility}

Total literacy for the countries under study were highly negatively correlated to MMR (r-0.87), NMR (r-0.87), IMR (r-0.95) and U5MR $(r-0.96)$ at $P<0.01$ respectively. Female literacy was negatively correlated to MMR ( -0.59$)$, NMR ( $r-0.7)$, IMR ( $r-0.74)$ and U5MR $(-0.72)$ at $P<0.05$ respectively as shown in Table 2 .

\section{Correlations of breastfeeding practices with mortality and malnutrition and other related causes of death by income group}

Table 3 compares breastfeeding practices associations with MRs by level of income. In the HIC there were significant correlations between EBF with NMR, IMR and U5MR at $\mathrm{P}<0.05$ and $M M R$ correlated highly with $\mathrm{BF} 12$ and $\mathrm{BF} 24$ months at $\mathrm{P}<0.01$. In MIC U5MR correlated with BF12 and deaths from NCD with BF24 months. In LIC TFS correlated with NMR and EBF was also correlated with BF12 at $\mathrm{P}<0.05$.

\section{Discussion}

Using multiple global health databases, we have quantified the associations between under-five mortality and exclusive breastfeeding in the presence of key socioeconomic and policy indicators in developing countries. Mean EBF in the region is low in many countries of the region ranging from $25 \pm 23.79$ in $\mathrm{LIC}$ to $35.6 \pm 16.63$ in MIC. Stunting and wasting rates in the region were associated with overweight and obesity. Low breastfeeding continuity rates by country were shown to be associated with the high trends in malnutrition as shown in Figure $\mathbf{2}$ and mortality in CU5 as shown in Figure 3. While indicators of malnutrition were closely associated with the high mortality rates in the countries with unstable economies.

Stunting and wasting are usually due to repeated exposure to communicable disease in CU5 [12]. Optimum breastfeeding practices have the potential of averting 1.4 million deaths every year among CU5 [12]. In fact, if coverage of EBF was set at 90 per cent this one preventive intervention could contribute to 13 percent reduction of mortality for this age group [13,14]. A review study identified several studies from Brazil, The Gambia, Ghana, Pakistan, the Philippines, and Senegal from which 1223 deaths of children under two years of age were studied [1]. In the African studies, virtually all babies were breastfed well into the second year of life, making it impossible to include them in the analyses of infant mortality. On the basis of the other three studies, protection provided by breastmilk declined steadily with age during infancy. In the first 6 months of life, protection against diarrhoea was substantially greater than against deaths due to acute respiratory infections and persisted up to 11 months of age [1]. For second-year deaths, the pooled odds ratios from five studies ranged between 1.6 and 2.1.

Our study demonstrated correlations between breastfeeding practices and mortality which were also significant when analyzed by income group, being highest among LIC between TFS and NMR [r-0.6] and for EBF with NMR, IMR and U5MR in HIC at $P<0.05$. A study in Ghana showed that there was a marked dose response of increasing risk of NMR with increasing delay in initiation of breastfeeding from 1 hour to day 7; overall late initiation [after day 1] was associated with a 2.4-fold increase in risk [11]. The risk of death as a result of infection increased with 
increasing delay in initiation of breastfeeding from the first hour to day seven; overall late initiation [after day one] was associated with a 2.6-fold risk. Partial breastfeeding was associated with a 5.7-fold adjusted risk of death as a result of infectious disease [11]. Another study showed no significant difference in the risk of death between children who were exclusively breastfed and those who were predominantly breastfed. Non-breastfed infants had a higher risk of dying when compared with those who had been predominantly breastfed [2]. Breastfeeding helps prevent hypothermia and hypoglycaemia in newborn babies, which are contributory causes of early neonatal deaths especially among low birth weight and premature babies [13]. During the late neonatal period, most deaths in developing countries are due to infections such as sepsis, acute respiratory tract infection, meningitis, omphalitis and diarrhoea. Feeding colostrum and breastfeeding, especially EBF, protects against such deaths $[19,20]$.

Human milk has a protective role in neonatal necrotizing enterocolitis [NEC] which is a disease with a poor prognosis in preterm babies and a leading cause for death in these babies [21]. NEC is considered to be caused by the coincidence of intestinal ischemia-reperfusion injury and systemic inflammation due to the colonization of pathogenic bacteria. Interleukin [IL]8 , a proinflammatory cytokine, plays an important role in the pathophysiology of NEC. It was recently reported that IL-1 $\beta$ activates the IL-8 gene by regulating the transcriptional nuclear factor $\mathrm{KB}[\mathrm{NF}-\mathrm{kB}$ ] signaling pathways in intestinal cells. Breast milk dramatically suppresses the IL- $1 \beta$-induced activation of the IL-8 gene promoter by inhibiting the activation pathway of NF-KB and induced the production of $I_{\kappa} B \alpha$ [22]. These results suggest that human breast milk could be protective and therapeutic in neonates with NEC by inhibiting the activation pathway of NF-KB [23].

The NEOVITA study group [10] examined the association between timing of breastfeeding initiation and post-enrolment neonatal and post-neonatal mortality up to 6 months of age, as well as the associations between breastfeeding pattern and mortality. They found that early initiation of breastfeeding reduces neonatal and early infant mortality both through increasing rates of EBF and by additional mechanisms.

In this study we found that TFS and EBF showed some degree of correlation with U5MR that was not statistically significant $[P>0.05]$. However, we found that U5MR was significantly associated with BF12 and BF24 months $[P<0.01]$. Another study [24] carried out associations between EBF and U5MR in 57 low- and-middle-income countries using data from the WHO and UNICEF databases covering the periods 2006-2014. They reported that EBF was independently associated with U5MR after adjusting for sociodemographic and health systems-related factors. They showed that a 10 percentage-points increase in EBF was associated with a reduction of 5 child deaths per 1,000 live births.

In our study we found that data from the region for stunting, wasting, parental illiteracy and TFR were highly correlated to U5MR. Other workers [24] reported a one-unit increase in
Human Development Index was associated with a decrease of 231 U5MR per 1,000 live births and that a \$100 increase in per capita health care expenditure was associated with a decrease of 2 child deaths per 1,000 live births. One unit increase in physician density was associated with 2.8 units decrease in the U5MR [24]. Population-level health system and socioeconomic factors exert considerable effect on the association between EBF and U5MR. Given that the health policy and socioeconomic indicators that influence EBF and U5MR are modifiable, the previous workers [24] suggest that policy makers could potentially target specific policies and programs to address national-level deficiencies in these sectors to reduce U5MR in the EMR countries [24]. In our study the strong correlations with literacy and TFR suggest that polices for improving literacy rates and birth spacing may play a role in reducing malnutrition and mortality in CU5.

In this study there was a negative correlation between TFS and BF12 and obesity in CU5. There is increasing evidence suggests that shortened duration of breastfeeding increase the risk to obesity $[25,26]$. Protein and total energy intake, as well as the amount of energy metabolised, are higher among formula-fed infants relative to breastfed [27], both higher protein intake [28] and weight gain [29] early in life is positively associated with the development of obesity later in childhood. Differences in release of insulin and other pancreatic and gut hormones have also been observed between breastfed and formula-fed infants, with formula feeding leading to higher plasma levels of insulin which in turn would stimulate fat deposition and early development of adipocytes, the cells that store fat [30]. Breast milk itself contains hormones and other biological factors involved in the regulation of food intake and energy balance which may help shape longterm physiological processes responsible for maintaining energy balance [31]. By moderating the impact of physiological processes that promote weight gain during infancy, breastfeeding might assist in "programming" an individual to be at reduced risk for overweight and obesity later in life [32].

In this study there was a high correlation between MMR and stunting and wasting in CU5 on one hand and adult obesity and overweight on the other hand. The mechanism by which MMR increases stunting and wasting could be through the direct effect of maternal morbidity during pregnancy on the increased prevalence on low-birth weight $[12,13]$. On the other hand, breastfeeding can influence MMR related deaths by reducing overweight and obesity related complications as cardiovascular disease especially related to hypertension and coronary heart disease $[19,33]$. Moreover, breastmilk can influence the genetic constitution of the body and alter its response to environmental facts. Telomeres are the protective nucleoprotein structures that cap the ends of chromosomes [34]. Telomere-sequence loss does not happen at a constant rate throughout life but rather is characterized by a rapid decline from birth through 4 years of age as a result of exposure to oxidative damage from chronic inflammation as obesity and chronic disease which renders telomeres particularly susceptible to reactive oxygen species-induced damage and more rapid telomere attrition. Meta-analyses of 16 adult studies have suggested an inverse association between adult BMI and leukocyte telomere length. 
The protective effect of breastfeeding against inflammation may explain the association between exclusive breastfeeding at 4-6 weeks of age and longer TL in the preschool years. The early introduction of nonmilk liquids and solids is associated with shorter TL at 4 and 5 y of age. Early exposure to certain foods may trigger an abnormal immune response to food antigens because the infant gut may be too immature before 4-6 months of age. The heightened immune response that is associated with early exposures to solid foods may also result in accelerated telomere aging [34].

However, many studies in the GCC countries [35-37] have reported a mean duration of breastfeeding is less than 12 months and that there is high use bottle feeding among Arab nationals from GCC countries than non GCC ones, which is consistent with our findings. Traditional beliefs that babies who are overweight are healthier make mothers add top feeds of formula which interferes with continuity and shortens duration of breastfeeding [38]. This could interpret our findings of overweight and obesity linked with HIC in the region under study [35-37].

In this study we also found that maternal education was associated with shorter duration of breastfeeding and mortality which is consistent with the findings of studies of women in Western countries [39] where breastfeeding duration was positively associated with level of maternal education. Another study in the Gulf reported that women with 12 or more years of education were less likely to have discontinued any or full breastfeeding compared with women with less than 12 years of education [40].

Interventions that promote and prolong breastfeeding duration include antenatal breastfeeding education [41], peer counseling [42], and improving health facility practices through the BFHI

\section{References}

1 WHO (2000) Effect of breastfeeding on infant and child mortality due to infectious diseases in less developed countries: A pooled analysis. WHO Collaborative Study Team on the Role of Breastfeeding on the Prevention of Infant Mortality. The Lancet. 355: 451-455.

2 Bahl R, Frost C, Kirkwood BR (2005) Infant feeding patterns and risks of death and hospitalization in the first half of infancy: Multicentre cohort study. Bulletin of the World Health Organization. 83: 418-426.

3 WHO (1989) Protecting, promoting and supporting breast-feeding: the special role of maternity services: A joint WHO/UNICEF statement. Geneva.

4 UNICEF/WHO (2009) Baby-friendly hospital initiative: Revised Updated and Expanded for Integrated Care. World Health Organization, Geneva.

5 WHO (2017) Guideline: Protecting, promoting and supporting breastfeeding in facilities providing maternity and newborn services. Geneva: World Health Organization; Licence: CC BY-NC-SA 3.0 IGO.

6 Geneva: United Nations Children's Fund (2005) Innocenti Declaration 2005 on infant and young child feeding, 22 November 2005, Florence, Italy.

7 Sankar MJ, Sinha B, Chowdhury R, Bhandari N, Taneja S, et al. (2015)
$[4,5]$. Breastfeeding support interventions should be available to all women, particularly those whose infants may be at greater risk as preterm sick babies and sick mothers and mothers with low education level and very high education or career seeking working women. The latter are very important as their children can attain higher IQ with improved breastfeeding, have better careers and improved income for themselves and for their country [43]. On the other hand, not breastfeeding carries significant risks for the mother and child $[44,45]$.

\section{Conclusion}

The results of our study support many previous studies that show that optimal early infant feeding practices influence nutritional status and early mortality rates in the neonatal, infancy and childhood periods as shown by the positive trends in-between country data for EBF and the corresponding data for nutritional status and mortality for each country. However, this study adds to these findings that continued breastfeeding for two years is an important predictor of early childhood mortality especially malnutrition. Moreover, parental literacy and fertility rates influence U5MR. Continued breastfeeding for two years influences early mortality and malnutrition rates. Much work needs to be exerted by countries to achieve the WHO targets for reducing global maternal mortality ratio to less than 70 deaths per 100,000 live births, and targets 2.2 for ending all forms of malnutrition, as malnutrition is a frequent cause of death for under-5 children [1].

\section{Acknowledgment}

Our acknowledgment to Afaf Tawfik MD, Director of NNI for her support in statistical analysis.

Optimal breastfeeding practices and infant and child mortality: A systematic review and meta-analysis. Acta Paediatr 104: 3-13.

8 Edmond KM, Zandoh C, Quigley MA, Amenga-Etego S, Owusu-Agyei $S$, et al. (2006) Delayed breastfeeding initiation increases risk of neonatal mortality. Pediatrics 117: e380-e386.

9 Huffman SL, Zehner ER, Victora C (2001) Can improvements in breastfeeding practices reduce neonatal mortality in developing countries? Midwifery. 17: 80-92.

10 NEOVITA study group (2016) Timing of initiation, patterns of breastfeeding, and infant survival: prospective analysis of pooled data from three randomized trials. The Lancet Global Health. 4: e266-e275.

11 Edmond KM, Kirkwood BR, Amenga-Etego S, Owusu-Agyei S, Hurt LS (2007) Effect of early infant feeding practices on infectionspecific neonatal mortality: an investigation of the causal links with observational data from rural Ghana. Am J Clin Nutr. 86: 1126-1131.

12 Sankar MJ, Sinha B, Chowdhury R, Bhandari N, Taneja S, et al. (2015) Optimal breastfeeding practices and infant and child mortality: a systematic review and meta-analysis. Acta Pediatrica 104: 3-13.

13 Victora CG, Bahl R, Barros AJ (2016) Breastfeeding in the 21st century: epidemiology, mechanisms, and lifelong effect. Lancet 387: 475-490.

14 Rollins NC (2016) Lancet breastfeeding series: Why invest, and 
what it will take to improve breastfeeding practices in less than a generation. Lancet 387: 491-504.

15 World Health Organization (2016) World Health Statistics 2016 Monitoring Health for the SDGs. (Sustainable Development Goals). World Health Organization, Geneva, Switzerland.

16 World Health Organization (2015) Eastern Mediterranean Region (EMR) Framework for health information systems and core indicators for monitoring health situation and health system performance for 2015 for the 22 countries of the EMR region.

17 World Health Organization (2017) Eastern Mediterranean Region (EMR) Framework for health information systems and core indicators for monitoring health situation and health system performance for 2017 for the 22 countries of the EMR region.

18 UNICEF data: Monitoring the situation of women and children. Multiple indicator cluster surveys (MICS). UNICEF.org.

19 Singh GK, Azuine RE, Siahpush M (2012) Global inequalities in cervical cancer incidence and mortality are linked to deprivation, low socioeconomic status and Human Development. International Journal of MCH and AIDS 1: 17-30.

20 Lamberti LM, Zakarija-Grković I, Fischer Walker CL (2013) Breastfeeding for reducing the risk of pneumonia morbidity and mortality in children under two: A systematic literature review and meta-analysis. BMC Public Health 13: S18.

21 Lucas A, Cole TJ (1990) Breast milk and neonatal necrotizing enterocolitis. Lancet 336: 1519-1523.

22 Minekawa R, Takeda T, Sakata M, Masami H, Isobe A, et al. (2004) Human breast milk suppresses the transcriptional regulation of IL$1 \beta$-induced NF-KB signaling in human intestinal cells. Am J Physio Cell Physiol. 287: C1404-C1411.

23 Kurscheid T, Holschneider AM (1993) Necrotizing enterocolitis (NEC): mortality and long-term results. Eur J Pediatr Surg. 3: 139-143.

24 Azuine RE, Murray, Alsafi N, Singh GK (2015) Exclusive Breastfeeding and Under-Five Mortality, 2006-2014: A Cross-National Analysis of 57 Low- and-Middle Income Countries. Int J MCH AIDS 4: 13-21.

25 Weyermann M, Rothenbacher D, Brenner H (2005) Duration of breastfeeding and risk of overweight in childhood: a prospective birth cohort study from Germany. International Journal of Obesity 30: 1281-1287.

26 Weng SF, Redsell SA, Swift JA, Yang M, Glazebrook CP (2012) Systematic review and meta-analyses of risk factors for childhood overweight identifiable during infancy. Archives of Disease in Childhood 97: 1019-1026.

27 Heinig MJ, Nommsen LA, Peerson JM, Lonnerdal B, Dewey KG (1993) Energy and protein intakes of breast-fed and formula-fed infants during the first year of life and their association with growth velocity: The DARLING Study. American Journal of Clinical Nutrition 58: 152-161.

28 Stettler N, Zemel BS, Kumanyika S, Stallings VA (2002) Infant weight gain and childhood overweight in a multicenter, cohort study. Pediatrics 109: 194-199.

29 Rolland-Cachera MF, Deheeger M, Akrout M, Bellisle F (1995) Influence of macronutrients on adiposity development: a follow up study of nutrition and growth from 10 months to 8 years of age. International Journal of Obesity and Related Metabolic Disorders 19: 573-578.

30 Lucas A, Sarson DL, Blackburn AM, Adrian TE, Aynsley-Green A, et al. (1980) Breast vs bottle: endocrine responses are different with formula feeding. Lancet 1: 1267-1269.

31 Savino F, Liguori SA, Fissore MF, Oggero R (2009) Breast milk hormones and their protective effect on obesity. International Journal of Pediatric Endocrinology 2009: 327505.

32 Von Kries R, Koletzko B, Sauerwald T, Von Mutius E, Barnert D, et al. (1999) Breast feeding and obesity: A cross sectional study. BMJ 319: 147-150.

33 Fall CH, Borja JB, Osmond C, Richter L, Bhargava SK, et al. (2011) Infant-feeding patterns and cardiovascular risk factors in young adulthood: data from five cohorts in low and middle-income countries. International Journal of Epidemiology 40: 47-62.

34 Wojcicki JM, Heyman MB, Elwan D, Lin J, Blackburn E, et al. (2016) Early exclusive breastfeeding is associated with longer telomeres in Latino preschool children. Am J ClinNutr. 104: 397-405.

35 Juaid DA, Binns CW, Giglia RC (2014) Breastfeeding in Saudi Arabia: A review. Int Breastfeed J 9: 1.

36 Radwan H (2013) Patterns and determinants of breastfeeding and complementary feeding practices of Emirati mothers in the United Arab Emirates. BMC Pub Health 13: 171.

37 Al-Kohji S, Said HA, Selim NA (2012) Breastfeeding practice and determinants among Arab mothers in Qatar. Saudi Med. J 33: 436-443.

38 Dashti M, Scott JA, Edwards CA, Al-Sughayer M (2014) Predictors of Breastfeeding duration among women in Kuwait: Results of a prospective cohort study. Nutrients 6: 711-728.

39 Rollins NC, Bhandari N, Hajeebhoy N, Horton S, Lutter CK, et al. (2016) Why invest, and what it will take to improve breastfeeding practices? Lancet 387: 491-504.

40 Lumbiganon P, Martis R, Laopaiboon M, Festin MR, Ho JJ (2011) Antenatal breastfeeding education for increasing breastfeeding duration. Cochrane Database of Systematic Reviews. 12: CD006425.

41 Morrow AL, Guerrero ML, Shults J, Calva JJ, Lutter C, et al. (1999) Efficacy of home-based peer counselling to promote exclusive breastfeeding: a randomised controlled trial. The Lancet. 353: 12261231.

42 Al-Nuaimi N, Katende G, Arulappan J (2017) Breastfeeding trends and determinants implications and recommendations for Gulf Cooperation Council countries. Sultan Qaboos University Med J 17: e155-e161.

43 Kim JI, Kim BN, Kim JW, Hong SB, Shin MS, et al. (2017) Breastfeeding is associated with enhanced learning abilities in school-aged children. Child Adolesc Psychiatry Ment Health 11: 36.

44 Stuebe A (2009) The risks of not breastfeeding for mothers and infants. Rev Obstet Gynecol 2:222-231.

45 The International Code of Marketing of Breast-milk Substitutes -2017 update: Frequently asked questions. World Health Organization, Geneva, Switzerland. 